\title{
The Role of Internal Audit from New Enterprise Risk Management Frameworks Perspective: Research in Turkey
}

\author{
Ahmet Onay 1 이
}

\begin{abstract}
Enterprise Risk Management (ERM) has emerged as a paradigm aimed at enabling organizations to respond to everchanging risk factors. Since the publication of the COSO Risk Management Framework and IIA report in 2004, internal audit functions have assumed a variety of roles in organizations' ERM operations. The main purpose of this study is to determine the extent to which internal auditors' activities have changed over time in relation to ERM activities and to what extent these tasks are undertaken in practice. In the first part, literature and new risk frameworks related to the role of internal audit in ERM are examined. In the study, data collected from 245 internal auditors working in organizations operating in Turkey were analyzed by t-test and analysis of variance (ANOVA). From the findings, it was determined that the opinions of internal auditors regarding ideal situations in terms of ERM tasks assumed under certain conditions differed from those in practice. The analyses showed that some of the internal auditors' opinions differed statistically according to demographic variables. It has been determined that the opinions of internal auditors differ according to age, professional experience and enterprise sector in which they worked. The results were compared with studies on different samples. Thus, internal auditors' opinions and the current situation in Turkey, can be compared to different regions. In our study, different results were obtained from the results of studies conducted in different countries.
\end{abstract}

\section{Keywords}

Internal Audit, Enterprise Risk Management, Role of Auditors, Turkey

\section{Introduction}

In recent years, the interest of employees, managers and internal auditors towards Enterprise Risk Management (ERM) has been increasing. Especially since recent financial crises, the fact that business stakeholders such as professional organizations, regulatory authorities and rating agencies have taken greater consideration of ERM than ever, explains this interest. Recent crises have highlighted weaknesses in risk management. Today, business executives face significant pressure to strengthen risk management systems and maintain stakeholder value. Regulatory agencies, professional organizations and other standard developers who put forward new risk management principles, rules and requirements increase this pressure.

\footnotetext{
1 Corresponding Author: Ahmet Onay (Ress. Asst.), Eskisehir Technical University, Vocational School of Transportation, Department of Management and Organization, Eskisehir, Turkey. E-mail: ahmet_onay@eskisehir.edu.tr ORCID: 0000-0003-1182-6003

To cite this article: Onay, A. (2020). Role of Internal audit from new enterprise risk management frameworks perspective: a research in Turkey. Istanbul Business Research, 49(2), 177-200. http://doi.org/10.26650/ibr.2020.49.0032
} 
In an economic environment where institutional uncertainty is increasing, ERM has emerged as a new paradigm for risk management. ERM argues that instead of relying on a traditional, functional strategy where each unit of the organization manages its own risk, a broader perspective that integrates and coordinates risk management across functions should be adopted. The enterprise-wide approach is designed to increase and maintain stakeholder value. However, ERM aims to do more than merely integrate risk management. The ERM definition made by COSO in 2004 was the most accepted (COSO, 2004, p.4):

“Enterprise risk management is a process, effected by an entity's board of directors, management and other personnel, applied in strategy setting and across the enterprise, designed to identify potential events that may affect the entity, and manage risk to be within its risk appetite, to provide reasonable assurance regarding the achievement of entity objectives."

The IIA is committed to implementing COSO guidelines and publications in risk management. The IIA definition made by IIA in 2004 is similar to and supports the definition of COSO (IIA, 2004, p.3):

"A structured, consistent and continuous process across the whole organization for identifying, assessing, deciding on responses to and reporting on opportunities and threats that affect the achievement of its objectives. "

In recent years, however, new needs have led to a metamorphosis in the mentality of ERM. COSO, which published the definition adopted by other professional organizations in 2004, did not remain indifferent to this metamorphosis and updated its ERM Framework and definition in 2017. One year after COSO, the International Organization for Standardization (ISO) updated the ISO 31000 guide, which are the most widely used guidelines in the field of ERM after COSO. In the current COSO guide, ERM is defined as (COSO, 2017, p.10):

"The culture, capabilities, and practices, integrated with strategy-setting and its execution, that organizations rely on to manage risk in creating, preserving, and realizing value."

Along with the framework published in 2004, the change in the traditional risk management approach focusing on risk mitigation has enabled internal audit to assume significant roles in risk management. The paradigm of the new risk frameworks, which argues that risk should be linked to strategy and performance, and that integrated activities are a necessity instead of functional efforts, has undoubtedly influenced internal audit. As a result of the guidance of IIA, which has changed the scope of the profession to a great extent, internal audit has evolved from a traditional control-based approach to a focal point of the profession to those who place risk management, corporate governance and value creation. Under the explicit guidance of the IIA for risk management, internal auditors make their profession an important part of risk management, and support their organizations in identifying and assessing risks. In 
recent years, the internal audit profession and risk management have changed in parallel. As a result, internal auditors theoretically made a significant contribution to ERM process locating them in a position which adds value to ERM practices.

In the following sections of the study, the theoretical background shaped by the new ERM frameworks, literature aiming to determine role of internal audit in ERM, methodology of research, findings and results obtained within the scope of research limitations are given respectively.

\section{Theorical Background and Literature Review}

The transformation of the corporate risk management approach in recent years has necessitated the update of two important frameworks. COSO has updated its ERM framework that it published for first time in 2004, taking into account changing conditions of business world and new emerging requirements. In 2016, it published a draft of the new framework, and in 2017, it adopted the framework supported by feedback of its stakeholders under the name of Enterprise Risk Management - Integrating with Strategy and Performance (Anderson, 2017). The second most widely used risk management framework in the world after the COSO framework was first published by ISO in 2009. ISO re-published its framework in 2018 under the name of ISO31000:2018 Risk Management Guidelines, taking into account the new challenges and changes facing businesses (Fox, 2018).

\section{New COSO ERM Framework}

The new COSO ERM framework has been prepared from a business process perspective in order to facilitate the integration of ERM activities and to increase the level of acceptance of practitioners consisting of top managers, board of directors, risk employees and internal auditors. It argues that an organization must integrate risk management activities that are often carried out separately from operational management and not linked to business processes (Pierce et al., 2016). The new corporate risk management approach wanted to prevent risk management in enterprise from being perceived as a progressive activity carried out by individuals independent of business processes. Because of the lack of integration between employees, processes and technologies complicates activities and prevents creation of the value that ERM can provide by providing insights and recommendations on business activities.

The new COSO ERM framework described a risk management model, which was previously composed of eight elements and described as cube, in a spiral of five interrelated elements (Prinsenberg \& Sluis, 2017, p.14; COSO, 2017, p.6). Figure 1 shows elements of the new framework. Governance regulates the management style of an organization that identifies risks of an organization, strengthens the corporate risk management structure and develops oversight 
responsibilities (Prewett \& Terry, 2018). Culture is about ethical values, desired behaviors and risk understanding in organizations. ERM works with strategic and objective setting activities in strategic planning processes. Risk appetite is determined and aligned with strategy. Business objectives are implemented through strategies while providing the basis for risk identification, assessment and development of appropriate responses. Achieving strategies and objectives is related to performance. Risks are prioritized according to their weight in terms of risk appetite. Organization then selects risk responses and creates a risk portfolio for the amount of risk it undertakes. The results of this process should be communicated to key risk stakeholders. An organization should review operating performance and how well the corporate risk management elements work due to significant changes over time, and which revisions are necessary, and revise as necessary. The ERM should establish communication channels that provide the necessary information from internal and external sources and share it when necessary. These channels should ensure continuous communication with both the top-down and bottom-up information sources and stakeholders that need to be communicated with outside the enterprise.

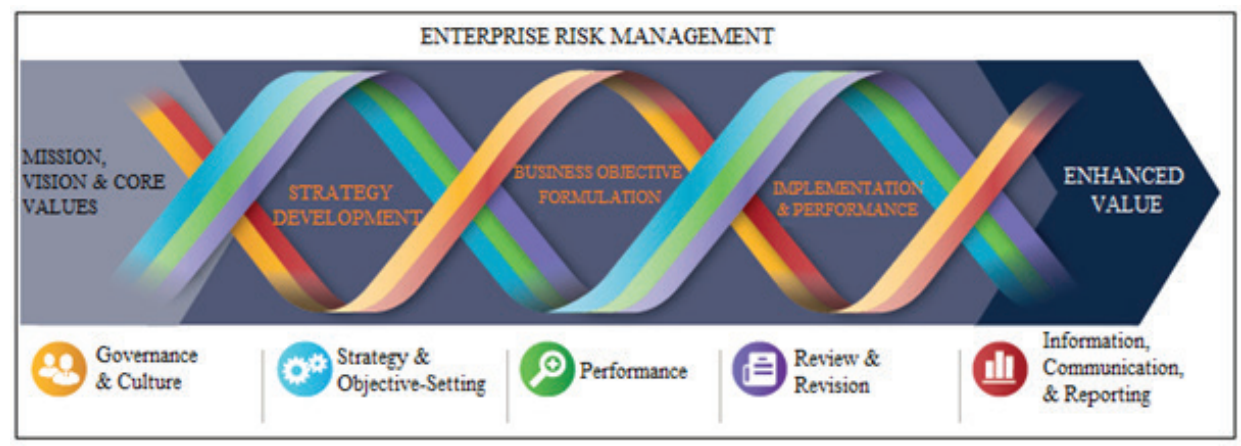

Figure 1. COSO ERM Helicase (COSO, 2017)

The new COSO Framework seeks to eliminate jargon risk and adopts a common business language to discuss concepts and practices. The framework argues that use of the same language will encourage the adoption of ERM by institutions. In traditional practice, although ERM refers to a business unit, team, or part of defense lines, a holistic view of the new framework provides a risk-based discussion of the culture, capabilities and activities used to manage risk in an enterprise.

The five components in the updated framework are supported by a set of policies. These principles cover all processes from governance to monitoring. These are principles that can be applied in different ways depending on the size of the firm, regardless of type of enterprise or sector in which it operates. Adherence to these principles may provide the senior management and board with a reasonable expectation to understand and manage risks that affect strategy and objectives in the entity. The new framework consists of 20 principles. The principles are shown in Table 1. 
Table 1

Principles of COSO ERM

\begin{tabular}{|c|c|c|c|c|}
\hline $\begin{array}{l}\text { Governance \& } \\
\text { Culture }\end{array}$ & $\begin{array}{l}\text { Strategy \& Objective- } \\
\text { Setting }\end{array}$ & Performance & $\begin{array}{l}\text { Review \& } \\
\text { Revision }\end{array}$ & $\begin{array}{l}\text { Information, } \\
\text { Communication, \& } \\
\text { Reporting }\end{array}$ \\
\hline $\begin{array}{l}\text { 1.Exercises Board Risk } \\
\text { Oversight 2.Establishes } \\
\text { Operating Structures } \\
\text { 3.Defines Desired } \\
\text { Culture 4.Demonstrates } \\
\text { Commitment to Core } \\
\text { Values 5.Attracts, } \\
\text { Develops, and Retains } \\
\text { Capable Individuals }\end{array}$ & $\begin{array}{l}\text { 6. Analyzes Business } \\
\text { Context } \\
\text { 7.Defines Risk Appetite } \\
\text { 8.Evaluates Alternative } \\
\text { Strategies 9.Formulates } \\
\text { Business Objectives }\end{array}$ & $\begin{array}{l}\text { 10.Identifies Risk } \\
\text { 11.Assesses Severity } \\
\text { of Risk 12.Prioritizes } \\
\text { Risks 13.Implements } \\
\text { Risk Responses } \\
\text { 14.Develops Portfolio } \\
\text { View }\end{array}$ & $\begin{array}{l}\text { 15.Assesses } \\
\text { Substantial Change } \\
\text { 16.Reviews Risk } \\
\text { and Performance } \\
\text { 17.Pursues } \\
\text { Improvement in } \\
\text { Enterprise Risk } \\
\text { Management }\end{array}$ & $\begin{array}{l}\text { 18.Leverages Infor- } \\
\text { mation and Technolo- } \\
\text { gy 19.Communicates } \\
\text { Risk Information } \\
\text { 20.Reports on Risk, } \\
\text { Culture, and Perfor- } \\
\text { mance Executive }\end{array}$ \\
\hline
\end{tabular}

The new framework highlights inter-function integration in ERM. It argues that risk should be linked to strategy setting and daily business activities. Thus, it helps to use ERM principles to promote value creation and preservation. The framework has been prepared from the perspective of business processes (Steffee, 2016). Risk-related concepts are discussed in terms of creating value that allows an organization to gain real benefits from ERM (Anders, 2019, p.66). The framework highlights relationship between risk and performance. It shows a new way of identifying and evaluating the relationship between risk level and performance. It argues that culture should be emphasized more. It argues that all risks that the organization is responsible for can be managed through an ERM model that reflects the changing demands and expectations of today's markets. To achieve this, the impact of business culture on values such as risk appetite and risk tolerance should be constantly considered.

The strategy setting process is an important field of activity in which corporate risk management should be integrated. Strategic errors are the main reason for the vast majority of losses in share value compared to operational failures. Strategies shaped by mission, vision and core values are the driving force of governance and business performance. Integrating with business activities and processes, ERM provides the development of a much more consistent information architecture that enables better decision-making and performance improvement. ERM should ensure that risk information is acted upon throughout the firm's value chain cycle.

ERM should be integrated into business strategy development, performance management, goal setting and governance processes. A holistic perspective can make risk management activities easier at various levels of enterprise, and act with risk information (Richtermeyer, 2018, p.25). Integrating ERM into business processes eliminates barriers to better information and communication structures and higher performance that support decision-making. Decisions that affect performance with risk information should be optimized and how decisions made affect the entity's risk profile (Sobel, 2018, p.16). 
The new framework argues that the evolving role of technology in ERM activities needs to be further taken into account and that technology has reached the potential to create more benefits in ERM. It enables discussion of how technology can affect an organization's strategy, business processes, and risk management (Prinsenberg \& Sluis, 2017, p.12).

The new COSO Framework emphasizes that it is important for corporate risk management to follow technological developments. ERM operations and capabilities need to adapt pace of changes and emerging risks in the business world. The principles of information, communication and reporting indicate that integrated risk and performance reporting has become a necessity for businesses. In order to develop strong ERM, businesses should use next generation data analytics and technologies, such as Big Data and Artificial Intelligence. Technology infrastructure will ensure the accuracy, completeness and timeliness of data in ERM (Herron \& Dholabhai, 2017, p.21).

There is no doubt that businesses will continue to face a future full of changes, complexities and uncertainties. ERM will be an important part of how an enterprise will be managed and guided in such periods. All organizations need to be able to respond consistently to change, including the ability to adapt quickly to capacity, while maintaining a high level of trust in stakeholders through strong decision-making processes. By focusing on the right issues, ERM can give businesses confidence in their ability to predict the future (Farrell \& Gallagher, 2015). The future needs to be adapted to achieve the predicted benefits of ERM. A future-oriented perspective reflects trends that need to be considered (COSO, 2017, p.7-8):

- ERM needs to adapt new data analytics technologies where more and more data can be analyzed faster. More data can be collected from both inside and outside of the enterprise and processed by new methods. Enhanced data analytics and visualization tools will improve understanding of both positive and negative impacts of risks and will be very useful for ERM activities.

- Today, many people think that we have entered an era of automatic processes and artificial intelligence. It is important to take into account the impact of automation, artificial intelligence, and future technologies to be discovered and the enhanced capabilities of ERM in operations and applications. With advanced technology tools, previously unrecognized relationships, trends and models can be revealed, providing a critical source of information for risk management.

- One concern that is often expressed by many business executives is the cost of risk management, compliance activities and control processes compared to value gained. As corporate risk management practices evolve, it will be important to effectively coordinate activities involving risk management, compliance, control and governance to provide maximum benefits to the organization. This may represent one of the best 
opportunities for ERM to redefine its importance for organization. ERM can be at the center of a structure, which ensures that risk management, compliance, control and governance activities are carried out at a lower cost, in coordination and cooperation.

\section{New ISO31000 ERM Framework}

In February 2018, ISO published a new risk management framework highlighting similar changes to COSO. However, there has been no change in the objective of integrating risk management of previous framework into strategic and operational processes. The importance of top management leadership, governance of the organization and integration of risk management were emphasized in the 2018 version of the framework. More emphasis was placed on the continuous repetitive nature of risk management. It was emphasized that information obtained and new analyses should ensure that processes, actions and controls are constantly revised. The scope of ERM has been reorganized to maintain a model of systems that can respond quickly to needs (IRM, 2018, p.8).

The new version of ISO 31000 is shorter than the previous version and provides a holistic overview of how risk management can be implemented. ISO 31000 defines principles and processes that characterize effective risk management. It is understood that the new ISO guidelines have the same risk management approach as the new COSO framework, places more emphasis on decision-making processes supported by risk knowledge, places value creation and protection at the center of its principles and advocates organizational and technological integration for effective risk management (IRM, 2018, p.9).

Th new guidelines state that ERM principles should be applied by all employees responsible for creating and maintaining value in risk management, decision-making, goal setting and performance improvement activities. Principles can be applied in any type and size of firm. ERM principles advocate that risk management should support organizations in terms of strategy setting, achieving objectives, and informed decision-making. Risk management should be a part of governance and leadership, and should form the basis of how to manage all organizational levels of enterprise. Eight principles of the new guidelines are (IRM, 2018, p.10):

1. ERM framework and processes should be customized to suit the business.

2. Timely participation of appropriate stakeholders is required.

3. A structural and comprehensive approach is required.

4. Risk management should be an integral part of all organizational activities.

5. Risk management anticipates, identifies, recognizes and responds to changes.

6. Risk management explicitly considers any limitations caused by available information. 
7. Human and cultural factors affect all aspects of risk management.

8. Risk management is continuously improved through learning and experience.

When the revisions made in both guidelines are examined, it is understood that the changes emphasize the need for further involvement of the senior management and board of directors in corporate risk management, that business objectives and strategies should be more associated with risk management and that the performance evaluation processes of the enterprise should be integrated with risk management. According to both guidelines, risk management has become an activity where business functions should work together. In summary, both guidelines emphasize the process of creating value through risk management and emphasize the need to place risk management decision-makers at the heart of risk management through organization of employees, processes and technology (Sobel, 2018; IRM, 2018).

\section{The Role of Internal Audit in ERM}

A professional information note issued by IIA in 1998 addressed the role of internal audit in risk management for the first time. The information note suggests that internal auditing should add value to an organization by closely linking with key concerns of senior executives and focusing on issues deemed important for success (Pickett, 2011, p. 84).

International Standards on Internal Auditing address the role and responsibilities of internal auditors in risk management. Performance Standard 2100 specifies that the internal audit function should assist an organization by assisting in the development of risk management and control processes and by identifying and assessing risks exposed. Thus, effective internal audit can become an integral part of organizations risk management processes, including the creation of appropriate corporate risk management.

According to standard 2100, internal auditors should assist both management and audit committee by examining, evaluating, reporting and developing remedial measures to assess the adequacy and effectiveness of risk processes implemented by management. However, it should be remembered that corporate management, the audit committee and board of directors are responsible for the risk management and control processes of an organization. Internal auditors who undertake consultancy tasks can provide assistance in identifying risks, assessing risks, implementing risk management methods, and taking and implementing risk-related control measures (IIA, 2010, p.167-168).

Internal auditors are in a position to better understand the concept of risk management than other employees and provide valuable advice (Flanders, 2018, p.62). Therefore, chief audit executive should be more proactive when training managers and the audit committee on the value of effective risk management (Wright, 2018). Internal auditors can play an important role in increasing this value (Thabit, 2019). In many internal audit activities, a risk-based 
model is used in preparation of audit plans prepared in line with data and requests from management. If the audit committee and management do not have a strong understanding of risk management, they cannot identify risk issues that arise and engage in appropriate activities. Internal auditors should shape the risk management approach of audit committee members and management (Cohen et al., 2017).

Internal audit, while adding value to an organization in ERM activities, is at risk of compromising its independence and objectivity. In view of this possibility, the IIA published its report titled "The Role of Internal Audit in Enterprise Risk Management" prepared by IIA$\mathrm{UK}$ and Ireland members in response to the publication of the COSO framework. This report demonstrates ways for internal auditors to maintain objectivity and independence required by IIA's professional standards, while providing assurance and advisory services to risk management processes. Tasks that internal audit function should and should not be involved in during ERM process are specified in the report.

The role of internal auditors in ERM is due to concerns that independence and objectivity will be harmed (Zwaan et al., 2011, p.588). In order to address this concern, the chief audit executive should include the scope of activities of internal audit charter and have audit committee approval. It should be declared that internal audit cannot manage risks on behalf of management, only contribute to the decision-making process with recommendations, and that all activities other than assurance services will be evaluated within the scope of consultancy services (Reding, 2013, p.4-18).

Table 2

Role of Internal Audit in Enterprise Risk Management

\begin{tabular}{ll}
\hline Core Internal Auditing Roles in ERM & Giving assurance on risk management processes \\
& Giving assurance that risks are correctly evaluated \\
& Evaluating risk management processes \\
& Evaluating the reporting of risks \\
& Reviewing the management of key risks \\
Legitimate internal auditing roles with & Facilitating identification and evaluation of risks \\
safeguards & Coaching management in responding to risks \\
& Coordinating ERM activities \\
& Consolidating the reporting on risks \\
& Maintaining and developing the ERM framework \\
& Championing establishment of ERM \\
& Developing risk management strategy for board approval \\
Roles internal auditing should not & Setting the risk appetite \\
undertake & Imposing risk management processes \\
& Management assurance on risks \\
& Taking decisions on risk responses \\
& Implementing risk responses on management's behalf \\
& Accountability for risk management \\
\hline
\end{tabular}


IIA Guideline points out that when internal auditors undertake legitimate consulting activities, which are defined as internal audit responsibilities that can be undertaken under certain circumstances, measures should be taken to ensure that they do not assume management responsibility to manage risks in a real sense. The internal audit charter approved by the audit committee is a logical measure to document the responsibilities of auditors in ERM. In addition, when auditors engage in any activities related to ERM, they should consider these tasks in consultation and take minimum care to implement relevant standards in order to maintain independence and objectivity (Gramling \& Myers, 2006, p.55). The conditions that enable internal auditors to undertake more tasks in ERM are presented in Table 3.

Table 3

Requirements for Internal Audit to Expand its Tasks in ERM

It should be clear that management remains responsible for risk management.

The nature of internal auditor's responsibilities should be documented in the internal audit charter and approved by the audit committee.

Requirements Internal auditing should not manage any of the risks on behalf of management.

for Internal Internal auditing should provide advice, challenge and support to management's

Audit to decision making, as opposed to taking risk management decisions themselves.

Expand its Internal auditing cannot also give objective assurance on any part of the ERM

Tasks framework for which it is responsible. Such assurance should be provided by other suitably qualified parties.

Any work beyond the assurance activities should be recognized as a consulting engagement and the implementation standards related to such engagements should be followed.

New risks and changing risk factors that affect the business world are forcing internal audit to expand its operations. The new frameworks have elaborated on the paradigm that the scope of risk management activities should be expanded from a holistic perspective. In order to adopt an integrated risk approach, internal auditors should carry limits of their risk management responsibilities to the highest possible level, taking into account certain situations. Internal audit standard 2120 legitimizes further engagement. According to 2120; "Internal audit activity should evaluate effectiveness of risk management processes and contribute to its improvement." As already stated in Standard 2010, "a risk-based plan consistent with objectives of organization to determine the priorities of internal auditing" can only be achieved through outputs from effectively functioning ERM.

The new COSO framework approved tasks of internal audit in risk management. According to the new framework, internal audit should support the identification of risk related problems and opportunity to evaluate by conducting audits or inspections on corporate risk management practices. Internal audit improves accountability by advising board of directors and senior management on matters requiring solutions. Internal audit function constitutes organization's independent line of defense or, in other words, last line of accountability mechanism. Two important factors that distinguish internal audit from other 
lines of defense are that they have a high level of independence and objectivity, and have authority to make recommendations to management to make assessments about design of processes and effectiveness of their operations (COSO, 2017, p.113).

Risk management activities for internal auditing have become increasingly important, especially with changes in the definition of the profession. The COSO framework and IIA report, published in 2004, are the first major milestones of the relationship between internal audit and risk management. Many studies in the literature have discussed dimensions of this relationship. The recently published COSO framework and new ISO31000 guidelines have the potential to drive discussions in the literature. A literature review consisting of studies examining the relationship between risk management and internal audit or evaluating duties and responsibilities of the internal audit function in ERM is given in Table 4.

In accordance with the scope of our study, the following main hypotheses have been formulated in the light of theoretical discussions on the responsibilities of internal audit regarding ERM and the results of past studies examining this subject.

$\mathbf{H}_{1}$. There is a statistically significant difference between internal auditors' opinions about the current situation and the ideal situation regarding their ERM responsibilities.

$\mathbf{H}_{2}$. There is a statistically significant difference between the opinions of internal auditors regarding ERM responsibilities according to their demographic characteristics.

$\mathbf{H}_{3}$. There is a statistically significant difference between internal auditors' opinions about the current situation and the ideal situation regarding the new ERM paradigm.

$\mathbf{H}_{4}$. There is a statistically significant difference between the opinions of internal auditors who are operating in different countries about their ERM responsibilities.

\section{Methodology}

"What are the responsibilities of internal audit within the scope of ERM?" and "To what extent do internal auditors assume responsibilities of ERM?" are the main research questions that guide the study. In this part of the study, the method of research which is designed to find answers to the research questions is explained. In this section, the universe of research and characteristics of sample and statistical analyses carried out within the scope of research are given. 
Table 4

Studies on ERM Responsibilities of Internal Audit

\begin{tabular}{lccc}
\hline PUBLICATION & SAMPLE & METHOD & FINDINGS \\
\hline Walker et al. (2002). & Five large-scale & Role of internal auditors in & Internal audit assumes important \\
Enterprise Risk Man- & global companies & ERM was investigated by & responsibilities especially in risk iden- \\
agement: Pulling It All & & case analysis. & tification and report preparation. \\
Together. & & &
\end{tabular}

Tillinghast-Towers, P. (2004). Adding Value Through Risk and Capital Management.

Beasley et al. (2005). ERM: A Status Report.

Mid-level and senior executives, including a small number of internal auditors of 101 large-scale companies from all over the world

Internal auditors and top managers of 175 large-scale companies

Gramling \& Myers (2006). Internal Auditing's Role in ERM.

361 internal auditors answered questions raised by the IIA to 7200 members worldwide.

Sarens \& Beelde (2006). Interviews were conInternal Auditors' Perception About Their Role In Risk Management: A Comparison Between US And Belgian Companies.

Beasley et al. (2005). Enterprise Risk Management: An Empirical Analysis of Factors Associate with The Extent of Implementation. scale companies from Belgium and the USA, taking into account the studies in theory.

175 responses were received to the questions sent to members through IIA, 52 problematic forms were drawn
A questionnaire consisting of 38 multiple choice questions was conducted. Results were analyzed by descriptive statistical methods and presented with tables and graphs.

Descriptive statistics were used on data obtained through the survey.

Obtained data were analyzed with descriptive statistics.

How qualitative auditors perceive their existing roles in risk management has been demonstrated through qualitative research. up, and a sample of 123 internal auditors was reached.

Obtained data were tested with logistic regression model.
Focal point of study is the applications of ERM. It has been determined that the internal audit function assumes limited responsibility for ERM.

It is understood that internal audit has developed close relations with the risk unit and managers. It has been determined that it undertakes duties in activities such as risk identification, coordination of activities and monitoring of processes.

It compared theoretical views on responsibilities defined by IIA in its report and the extent to which responsibilities are assumed in practice. It is determined that internal audit's ERM activities are generally in line with IIA reports.

It is understood that the role of internal audit in ERM is related to the development of risk management. Acceptance of ERM responsibilities and awareness of ERM benefits by senior management facilitates work of internal audit.

It has been determined that ERM has a significant impact on internal audit activities. The factors such as desire of audit committee and senior managers to benefit from internal audit in ERM, term of internal audit manager, sector in which it operates and leadership role of internal audit in ERM have been determined to affect internal audit activities. 
Table 5

Studies on ERM Responsibilities of Internal Audit (Continuation of Table 4)

\begin{tabular}{lccc}
\hline PUBLICATION & SAMPLE & METHOD & FINDINGS \\
\hline $\begin{array}{l}\text { Fraser \& Henry (2007). } \\
\text { Embedding Risk Man- } \\
\text { agement: Structures and } \\
\text { Approaches. }\end{array}$ & $\begin{array}{c}\text { Four finance direc- } \\
\text { tors, four chairmen of } \\
\text { the audit committee, } \\
\text { four internal auditors } \\
\text { and one risk manager } \\
\text { of five large-scale }\end{array}$ & $\begin{array}{c}\text { In order to reveal role of } \\
\text { internal auditors and audit } \\
\text { committees in risk manage- } \\
\text { ment, a qualitative research } \\
\text { design was conducted } \\
\text { through face-to-face inter- }\end{array}$ & $\begin{array}{c}\text { It has been determined that internal } \\
\text { auditors assume a significant portion } \\
\text { of risk management responsibilities } \\
\text { that must remain in management. }\end{array}$ \\
$\begin{array}{c}\text { terviewed. Data were } \\
\text { also collected from }\end{array}$ & $\begin{array}{c}\text { Findings show that undertaking } \\
\text { tasks that the IIA does not consider } \\
\text { appropriate for internal auditors on }\end{array}$ \\
& & $\begin{array}{c}\text { ERM threatens the objectivity of the } \\
\text { profession. }\end{array}$
\end{tabular}

Castanheira, et al. (2010). Factors Associated with The Adoption of Risk-Based Internal Auditing.

Zwaan et al. (2011). Internal Audit Involvement in Enterprise Risk Management.
Data were collected from 117 certified internal auditors from IIA-Australia.
Paape \& Speklé (2012). The Adoption and Design of Enterprise Risk Management Practices: An Empirical Study.

Shortreed et al. (2012). The Future Role of Internal Audit in (Enterprise) Risk Management.
928 responses were received from questionnaire sent to 9339 employees with specific characteristics of Dutch origin, and 825 questionnaires were analyzed after unsuitable forms were removed.

Responsibilities of internal audit in ERM are examined within scope of current literature, COSO and ISO frameworks.
In order to investigate company-specific factors affecting adoption of risk-based audit and role of internal audit in ERM, a questionnaire including a number of questions was prepared. Descriptive statistics, percentages and Chi-Square test were used.

Statements that define responsibilities in the IIA risk management report of internal audit have been transformed into a questionnaire consisting of two columns describing current and ideal situation. In addition, questions related to use of ERM were included. Obtained data were analyzed

by Anova and t-test.

Questionnaire used in study was prepared by an expert team and tested as a pilot study on a small number of internal auditors and risk employees. Logistic Regression Model consisting of many independent variables was tested.

It is theoretically discussed what future responsibilities of internal auditing are likely to emerge within the scope of ERM.
It has been determined that internal audit assumes greater responsibility for ERM in small enterprises. In addition, the role of internal auditing in ERM has become more important in the private sector, especially in enterprises operating in risky sectors such as finance.

Results show that a significant number of enterprises engage in ERM operations and place responsibilities on their internal auditors in line with the IIA report. Results were compared with previous studies (Gramling \& Myers, 2006).

Effects of factors such as governance codes, ownership structure, presence of audit committee, audit firm, sector of operation and business size on design of ERM activities were examined. Findings provide clues about impact of internal audit, audit committee, and audit firm on ERM.

In particular, IIA reports and risk management frameworks were examined and important results were obtained. Internal audit should update its responsibilities to support risk management to varying circumstances. 
The new frameworks advocate an approach that advocates expanding the scope of internal audit risk management activities from an integrated perspective. It emphasizes the need for internal auditors to maximize their mandate to the highest possible level, provided that certain circumstances are taken into account. The main purpose of this study is to determine the current ERM responsibilities of internal audit in the line with economic conjuncture and technological developments and to determine the level at which these responsibilities are assumed in practice. Opinions reached in the framework of the research sample showed what level of tasks internal auditors undertake in their organizations under ERM in Turkey. ERM awareness levels were also determined. Perspectives obtained as a result of the research will enable internal auditors to develop their professional activities. Results of the research are important in terms of guiding that activities that would harm the professional objectivity and independence of internal audit are not included in job description.

Another important purpose of our study is to compare findings of internal auditors who are working in Turkey regarding ERM duties and participation with similar studies in the literature. We compared the findings of our study with the results of two different studies. These are researches conducted by Gramling \& Myers (2006) on an international sample of IIA member participants from many different parts of the World and conducted by Zwaan et al. (2011) on a sample of participants from the Institute of Internal Auditors of Australia (IIAA). Thus, different samples were compared with the sample from Turkey.

The target population of our study consists of internal auditors. Taking into consideration cost and time constraints, accessible population was determined as internal auditors who are members of TIDE (Turkey Institute of Internal Auditors). According to the 2018 annual report of TIDE, 2667 internal auditors are members of TIDE. Assistance was received from TIDE to collect data from internal auditors. TIDE was data collection forms, which we have transferred to an electronic environment, to all its members twice. The entire accessible population was reached and feedback from 254 participants was achieved. As a result of the examination, 9 questionnaires that were filled out incorrectly or incompletely were excluded from the research and 245 questionnaires were analyzed.

In the first part of the questionnaire, questions were asked to determine age, gender (Female / Male), professional experience and sector in which the organization operates (Private / Public). In addition, the risk management model used in the enterprise was asked as an open ended question. The second part of the questionnaire consists of 17 twins (ideal / current) questions constructed with the Likert scale (Strongly Disagree $=1$, Strongly Agree $=5$ ). The questionnaire items were formulated as questions in the 5-point Likert format of the Core Internal Auditing Roles in ERM, Legitimate Internal Auditing Roles with Safeguards, and Roles Internal Auditing Should not Undertake included in IIA's position reports. Many studies in the literature refer to the IIA's report titled The Role of Internal Audit in ERM and used defended 
statements in their research. Utilizing the IIA reports within the scope of the research has provided a more accurate determination of responsibilities of internal audit for the purposes of our study, as well as comparing the results of research with studies in the literature.

Descriptive statistics related to sampling were used in the research. In order to reveal the differences between views of sample on ideal situation and current situation, $t$ tests were conducted. Analysis of variance (ANOVA) was used to test the effect of the descriptive characteristics of the research sample on opinions and to compare the results of our study with the results of other studies in the literature. SPSS 24.0 was used for descriptive and predictive analyses.

\section{Findings}

In this section, the demographic characteristics of the sample and statistical analyses are given. Before statistical analyses were performed, normality, which is the prerequisite for analyses, was tested. Since the data set consisted of ordinal variables based on significance or superiority, the distribution of data was examined by a graphical approach and kurtosis-skewness values instead of test statistics measuring normality. In the literature, there are studies advocating that kurtosis-skewness limit values should be between +1.5 and -1.5 (Tabachnik $\&$ Fidell, 2007) or +2 and -2 (George \& Mallery, 2010). When graphs and kurtosis-skewness values were examined, it was concluded that the data set was distributed close to the normal distribution and that normality assumption was not violated.

The second part of the questionnaire consists of "core roles", "legitimate roles with safeguards" and "roles that should never be undertaken". In order to determine internal consistency of the questionnaire, the Cronbach Alpha coefficient was calculated for each question group. Cronbach's alpha coefficient was calculated as $\alpha=0.947$ for core tasks, $\alpha=0.872$ for tasks that could be undertaken under certain conditions and $\alpha=0.849$ for tasks that should never be undertaken. It was determined from the obtained values that internal consistency, which is an important indicator of the reliability of the questionnaire, was quite high.

The demographic characteristics of the internal auditors participating in our research are presented in Table 6. Internal auditors are classified according to their gender, age and professional experience. The majority of internal auditors who participated in the survey were male $(66 \%)$, older than 40 years (35\%) and with over 7 years of professional experience (58\%).

\section{Comparison of Opinions in Terms of Ideal Situation and Current Situation}

In order to compare participants' views on the ideal situation and the current situation of internal auditors on ERM tasks, the paired sample $t$ test, which is frequently used in statistical literature, was used to evaluate the responses of the same group to two different questions. Results of the test are presented in Table 7. 
Table 6

Demographic Characteristics of Sample

\begin{tabular}{lccc}
\hline & Business Sector & Total \\
\hline Gender & Private & Public & \\
Female & 74 & 10 & $84(34 \%)$ \\
Male & 128 & 33 & $161(66 \%)$ \\
Age & & & $80(33 \%)$ \\
Under 34 & 80 & - & $79(32 \%)$ \\
Between 34-40 & 73 & 6 & $86(35 \%)$ \\
Over 40 & 49 & 37 & $72(29 \%)$ \\
Professional Experience & & 3 & $74(30 \%)$ \\
Under 7 Years & 69 & 20 & $67(28 \%)$ \\
Between 7-12 & 54 & 20 & $32(13 \%)$ \\
Over 12 Years & 47 & - & $\mathbf{2 4 5 ( 1 0 0 \% )}$ \\
Not Reply & 32 & $43(18 \%)$ & \\
\end{tabular}

Table 7

Paired Samples $t$ Test Results

\begin{tabular}{lccc}
\hline & Business Sector & Total \\
\hline Gender & Private & Public & \\
Female & 74 & 10 & $84(34 \%)$ \\
Male & 128 & 33 & $161(66 \%)$ \\
Age & & & $80(33 \%)$ \\
Under 34 & 80 & - & $79(32 \%)$ \\
Between 34-40 & 73 & 6 & $86(35 \%)$ \\
Over 40 & 49 & 37 & $72(29 \%)$ \\
Professional Experience & & 3 & $74(30 \%)$ \\
Under 7 Years & 69 & 20 & $67(28 \%)$ \\
Between 7-12 & 54 & 20 & $32(13 \%)$ \\
Over 12 Years & 47 & - & $\mathbf{2 4 5}(\mathbf{1 0 0 \% )}$ \\
Not Reply & 32 & $43(18 \%)$ & \\
\end{tabular}

${ }^{*} \mathrm{p}<.01(\mathrm{t}>2.58)$

According to the test results, a statistically significant difference was found only between the opinions of participants regarding tasks undertaken under certain conditions. The difference is in favor of ideal situation.

\section{Comparison of Opinions in Terms of Demographic Characteristics}

Independent samples t test should be conducted to test the statistical significance of the difference between the means of the views of two unrelated participants. It was tested whether the opinions of participants changed according to gender and sector 
(Private / Public) in which the enterprise of the internal auditors operates. Results showed that the opinions did not change according to gender. On the other hand, the fact that the firm to which the internal auditors belonged to operates in the private or public sector affected their opinions. Equality of variance should be examined when evaluating the test results and appropriate values should be considered according to the Levene Test results. Results of theindependent sample t test conducted to determine whether opinions of internal auditors vary according to sector in which they operate are shown in Table 8.

Table 8

Independent Samples $t$ Test Results

\begin{tabular}{|c|c|c|c|c|c|c|c|c|}
\hline Ideal Situation & Group & $\mathbf{n}$ & $\overline{\mathbf{X}}$ & $\Delta \overline{\mathbf{X}}$ & SS & SD & $\mathbf{t}$ & p \\
\hline \multirow[t]{2}{*}{ Core Tasks } & Private & 202 & 4.13 & 0.344 & 0.626 & 243 & $3.23 *$ & 0.001 \\
\hline & Public & 43 & 3.79 & & 0.674 & & & \\
\hline \multirow{2}{*}{$\begin{array}{l}\text { Legitimate tasks with } \\
\text { safeguards }\end{array}$} & Private & 202 & 3.09 & -0.355 & 0.540 & 243 & $-3.28 *$ & 0.002 \\
\hline & Public & 43 & 3.45 & & 0.665 & & & \\
\hline \multirow[t]{2}{*}{ Tasks should not undertake } & Private & 202 & 1.93 & 0.282 & 0.624 & 243 & 2.21 & 0.030 \\
\hline & Public & 43 & 1.65 & & 0.783 & & & \\
\hline Current Situation & Group & $\mathrm{n}$ & $\bar{X}$ & $\Delta \overline{\mathrm{X}}$ & SS & $\mathrm{SD}$ & $\mathrm{t}$ & $\mathrm{p}$ \\
\hline \multirow[t]{2}{*}{ Core Tasks } & Private & 202 & 4.25 & 0.576 & 0.449 & 243 & $5.97 *$ & 0.000 \\
\hline & Public & 43 & 3.67 & & 0.596 & & & \\
\hline \multirow{2}{*}{$\begin{array}{l}\text { Legitimate tasks with } \\
\text { safeguards }\end{array}$} & Private & 202 & 2.76 & -0.766 & 0.663 & 243 & $-10.19 *$ & 0.000 \\
\hline & Public & 43 & 3.52 & & 0.386 & & & \\
\hline \multirow[t]{2}{*}{ Tasks should not undertake } & Private & 202 & 1.89 & 0.105 & 0.421 & 243 & 1.50 & 0.133 \\
\hline & Public & 43 & 1.78 & & 0.385 & & & \\
\hline
\end{tabular}

${ }^{*} \mathrm{p}<.01(\mathrm{t}>2.58)$

When Table 8 is examined, it is determined that the opinions of participants regarding both the ideal situation and the current situation differ statistically at the level of $p<.01$ in terms of "core tasks" and "legitimate roles with safeguards" according to the sector in which the enterprise operates. While the opinions of private sector employees on "core tasks" are higher in terms of both ideal situation and current situation, the opinions of public sector employees on "legitimate tasks with safeguards" are higher in both the ideal situation and the current situation.

One-way analysis of variance (ANOVA) was conducted to assess whether age and professional experience had an impact on opinions. As presented in the table of demographic characteristics of sample, age and professional experience variables were classified into three groups. One-way ANOVA test was used to determine whether there was a significant difference between the mean scores of the opinions for three groups. The Scheffe test was applied to determine the difference between the groups for means where significant differences were detected. Results of ANOVA test for age independent variable are presented in Table 9. 
Table 9

ANOVA Test Results According to Age Variable

\begin{tabular}{|c|c|c|c|c|c|c|c|}
\hline Ideal Situation & Group & $\mathbf{n}$ & $\overline{\mathbf{X}}$ & SS & SD & $\mathbf{F}$ & $\mathbf{P}$ \\
\hline \multirow[t]{3}{*}{ Core Tasks } & Under 34 & 80 & 4.15 & 0.622 & 242 & $4.10^{*}$ & 0.018 \\
\hline & Between 34-40 & 79 & 4.16 & 0.651 & & & \\
\hline & Over 40 & 86 & 3.91 & 0.643 & & & \\
\hline \multirow{3}{*}{$\begin{array}{l}\text { Legitimate tasks with } \\
\text { safeguards }\end{array}$} & Under 34 & 80 & 3.10 & 0.523 & 242 & 1.13 & 0.325 \\
\hline & Between 34-40 & 79 & 3.13 & 0.502 & & & \\
\hline & Over 40 & 86 & 3.23 & 0.683 & & & \\
\hline \multirow[t]{3}{*}{ Tasks should not undertake } & Under 34 & 80 & 1.83 & 0.556 & 242 & 0.52 & 0.590 \\
\hline & Between 34-40 & 79 & 1.94 & 0.612 & & & \\
\hline & Over 40 & 86 & 1.87 & 0.787 & & & \\
\hline Current Situation & Group & $\mathrm{n}$ & $\overline{\mathrm{X}}$ & SS & SD & $\mathrm{F}$ & $\mathrm{P}$ \\
\hline \multirow[t]{3}{*}{ Core Tasks } & Under 34 & 80 & 4.27 & 0.430 & 242 & $3.77 *$ & 0.024 \\
\hline & Between 34-40 & 79 & 4.12 & 0.464 & & & \\
\hline & Over 40 & 86 & 4.05 & 0.631 & & & \\
\hline \multirow{3}{*}{$\begin{array}{l}\text { Legitimate tasks with } \\
\text { safeguards }\end{array}$} & Under 34 & 80 & 2.73 & 0.715 & 242 & $10.10^{*}$ & 0.000 \\
\hline & Between 34-40 & 79 & 2.78 & 0.643 & & & \\
\hline & Over 40 & 86 & 3.15 & 0.632 & & & \\
\hline \multirow[t]{3}{*}{ Tasks should not undertake } & Under 34 & 80 & 1.79 & 0.397 & 242 & 2.28 & 0.104 \\
\hline & Between 34-40 & 79 & 1.93 & 0.398 & & & \\
\hline & Over 40 & 86 & 1.88 & 0.443 & & & \\
\hline
\end{tabular}

* There is a significant difference between groups.

According to the results of the ANOVA test, it was determined that the opinions of participants about the ideal situation and the current situation differed statistically according to age variable in terms of core tasks. Post-hoc test results to determine which age groups differ in terms of core tasks showed that the difference was between the views of the 34-40 age group and the over 40 age group in terms of ideal situation. In addition, the opinions of participants about practice differed significantly according to age variable in terms of tasks assumed under certain conditions. Posthoc tests show that the difference is between the views of the under-34 and over-40 groups. On the other hand, there is no significant difference in terms of tasks that should never be undertaken.

One-way analysis of variance (ANOVA) was conducted to determine whether opinions of internal auditors changed according to their professional experience. Results of analysis are presented in Table 10.

Results of ANOVA test conducted according to the professional experience variable showed that the opinions of participants differed only in terms of tasks assumed under certain conditions. Post-hoc test results in order to determine the differences between the groups showed that there was a difference between the opinions of participants who had less than 7 years of experience and those who had more than 12 years of experience. 
Table 10

ANOVA Test Results According to Professional Experience

\begin{tabular}{|c|c|c|c|c|c|c|c|}
\hline Ideal Situation & Group & $\mathbf{n}$ & $\overline{\mathbf{X}}$ & SS & SD & $\mathbf{F}$ & $\mathbf{P}$ \\
\hline \multirow[t]{3}{*}{ Core Tasks } & Under 7 Year & 72 & 4.26 & 0.591 & 242 & 2.93 & 0.055 \\
\hline & Between 7-12 Years & 74 & 4.10 & 0.678 & & & \\
\hline & Over 12 Year & 67 & 4.00 & 0.629 & & & \\
\hline \multirow{3}{*}{$\begin{array}{l}\text { Legitimate tasks with } \\
\text { safeguards }\end{array}$} & Under 7 Year & 72 & 3.12 & 0.520 & 242 & 1.33 & 0.264 \\
\hline & Between 7-12 Years & 74 & 3.23 & 0.570 & & & \\
\hline & Over 12 Year & 67 & 3.27 & 0.660 & & & \\
\hline \multirow[t]{3}{*}{ Tasks should not undertake } & Under 7 Year & 72 & 1.91 & 0.558 & 242 & 0.70 & 0.495 \\
\hline & Between 7-12 Years & 74 & 1.83 & 0.746 & & & \\
\hline & Over 12 Year & 67 & 1.96 & 0.694 & & & \\
\hline Current Situation & Group & $\mathrm{n}$ & $\overline{\mathrm{X}}$ & SS & $\mathrm{SD}$ & $\mathrm{F}$ & $\mathrm{P}$ \\
\hline \multirow[t]{3}{*}{ Core Tasks } & Under 7 Year & 72 & 4.22 & 0.419 & 242 & 2.05 & 0.130 \\
\hline & Between 7-12 Years & 74 & 4.05 & 0.547 & & & \\
\hline & Over 12 Year & 67 & 4.11 & 0.541 & & & \\
\hline \multirow{3}{*}{$\begin{array}{l}\text { Legitimate tasks with } \\
\text { safeguards }\end{array}$} & Under 7 Year & 72 & 2.76 & 0.699 & 242 & $6.51^{*}$ & 0.002 \\
\hline & Between 7-12 Years & 74 & 2.93 & 0.718 & & & \\
\hline & Over 12 Year & 67 & 3.17 & 0.581 & & & \\
\hline \multirow[t]{3}{*}{ Tasks should not undertake } & Under 7 Year & 72 & 1.86 & 0.380 & 242 & 0.82 & 0.437 \\
\hline & Between 7-12 Years & 74 & 1.83 & 0.418 & & & \\
\hline & Over 12 Year & 67 & 1.92 & 0.444 & & & \\
\hline
\end{tabular}

* There is a significant difference between groups.

\section{Comparison of Opinions on New ERM Paradigm}

In the questionnaire form of research, question items that are not included in the IIA Role of Internal Audit in Corporate Risk Management Report, which is the focus of our study, are also included. These are the potential tasks of internal audit, reflecting the new paradigm that is emphasized in the new ERM frameworks. The participants' opinions about the ideal situation and the current situation were analyzed by the t test. In addition, participants were asked open-ended about the risk management model used in their businesses. Findings are presented in Table 11.

Table 11

Comparison of Opinions on New ERM Paradigm

\begin{tabular}{|c|c|c|c|c|c|c|c|c|}
\hline Item Statement & Measure & $\mathbf{n}$ & $\overline{\mathbf{X}}$ & $\Delta \overline{\mathbf{X}}$ & $\Delta \mathrm{SS}$ & SD & $\mathbf{t}$ & $\mathbf{p}$ \\
\hline \multirow{2}{*}{$\begin{array}{l}\text { Internal audit contributes to use of a common } \\
\text { language to discuss risk in enterprise. }\end{array}$} & Ideal Situation & 245 & 3.96 & 0.302 & 0.772 & 244 & 6.12 & 0.000 \\
\hline & Current & & 3.66 & & & & & \\
\hline \multirow{2}{*}{$\begin{array}{l}\text { Internal audit has the knowledge of software to } \\
\text { guide IT professionals as needed. }\end{array}$} & Ideal Sit & 245 & 4.41 & 0.318 & 0.771 & 244 & 6.46 & 0.000 \\
\hline & Current Situation & & 4.09 & & & & & \\
\hline \multirow{2}{*}{$\begin{array}{l}\text { Internal audit encourages use of technologies } \\
\text { that provide continuous audit. }\end{array}$} & Ideal Situation & 245 & 4.43 & 0.355 & 0.665 & 244 & 8.35 & 0.000 \\
\hline & Current Situation & & 4.07 & & & & & \\
\hline
\end{tabular}

${ }^{*} \mathrm{p}<.01(\mathrm{t}>2.58)$ 
According to the results of the paired samples $t$ test, a statistically significant difference was found between the opinions about the three question items. This difference is in favor of the ideal situation for all three question items.

Answers given to the open-ended question in Table 12 showed that the most commonly used framework in risk management is COSO ERM.

Table 12

Open Ended Questions Answers Given

What is the most commonly used risk management model in your business?

\begin{tabular}{lcccccccc}
\hline & COSO & ISO & BDDK & GRC & Own Model & COBIT & No answer \\
\hline Frequency $(n=245)$ & 142 & 24 & 8 & 8 & 6 & 3 & 54 \\
\hline
\end{tabular}

\section{Comparison of Research Findings with Similar Studies}

Our findings obtained from TIDE member participants within the scope of our study, were compared with studies of Gramling \& Myers (2006) and Zwaan et al. (2011). The means of opinions of our study and participants of these two studies about core tasks, legitimate tasks with safeguards and tasks that should not undertaken in IIA report are presented in Table 13.

Table 13

Comparison of Present Research and Other Research

\begin{tabular}{|c|c|c|c|c|c|c|}
\hline & \multicolumn{3}{|c|}{ Ideal Situation } & \multicolumn{3}{|c|}{ Current Situation } \\
\hline & $\begin{array}{c}\text { Present } \\
\text { Research }\end{array}$ & G\&M & $\mathbf{Z W}$ & $\begin{array}{c}\text { Present } \\
\text { Research }\end{array}$ & G\&M & $\mathbf{Z W}$ \\
\hline \multicolumn{7}{|l|}{ Core Tasks $(n=245)$} \\
\hline Giving assurance on risk management processes & 4.27 & 3.80 & 4.05 & 4.32 & 3.10 & 3.71 \\
\hline Giving assurance that risks are correctly evaluated & 4.02 & 3.60 & 3.63 & 4.04 & 3.00 & 3.18 \\
\hline Evaluating risk management processes & 4.03 & 3.82 & 3.98 & 4.12 & 3.17 & 3.44 \\
\hline Evaluating the reporting of risks & 4.04 & 3.70 & 3.77 & 4.08 & 3.09 & 3.05 \\
\hline Reviewing the management of key risks & 4.02 & 3.76 & 3.95 & 4.17 & 3.19 & 3.39 \\
\hline \multicolumn{7}{|l|}{ Legitimate Tasks with Safeguards $(n=245)$} \\
\hline Facilitating identification and evaluation of risks & 3.26 & 3.50 & 2.96 & 2.95 & 3.38 & 2.84 \\
\hline Coaching management in responding to risks & 3.18 & 3.11 & 2.81 & 2.86 & 2.84 & 2.66 \\
\hline Coordinating ERM activities & 3.17 & 2.75 & 2.19 & 2.91 & 2.47 & 2.30 \\
\hline Consolidating the reporting on risks & 3.11 & 3.10 & 2.32 & 2.92 & 2.87 & 2.39 \\
\hline Maintaining and developing the ERM framework & 3.18 & 2.73 & 2.17 & 2.86 & 2.49 & 2.30 \\
\hline Championing establishment of ERM & 3.05 & 3.27 & 2.96 & 2.87 & 2.88 & 2.94 \\
\hline \multicolumn{7}{|l|}{ Tasks should not undertake $(\mathrm{n}=\mathbf{2 4 5})$} \\
\hline Setting the risk appetite & 1.84 & 1.89 & 1.63 & 1.93 & 1.81 & 1.62 \\
\hline Imposing risk management processes & 1.73 & 2.30 & 1.83 & 1.79 & 2.19 & 1.97 \\
\hline Management assurance on risks & 1.90 & 2.64 & 3.17 & 1.76 & 2.41 & 3.04 \\
\hline Taking decisions on risk responses & 1.89 & 2.14 & 1.86 & 1.97 & 2.07 & 1.89 \\
\hline Implementing risk responses on management's behalf & 1.84 & 1.90 & 1.30 & 1.77 & 1.88 & 1.39 \\
\hline Accountability for risk management & 2.09 & 2.26 & 1.68 & 2.00 & 2.17 & 1.81 \\
\hline
\end{tabular}


Differences were found between the findings of our study and the findings of the other two studies. The opinion on core tasks and tasks assumed under certain conditions of internal auditors in Turkey is higher than in terms of both the ideal situation and the current situation. On the other hand, their views on tasks that should never be undertaken are lower. If Table 13 is analyzed, it is understood that the means of views increases in terms of basic tasks and tasks that should never be undertaken according to topicality of the research.

\section{Results and Recommendations}

The International Internal Auditing Standards place internal auditors in a proactive position that adds value to the risk management activities of their organizations. The new risk factors that challenge businesses provide an opportunity to add value to their organizations for the internal audit profession. Internal auditors for this purpose must expand the scope of their activities in the direction of ERM. Adoption of a holistic risk approach advocated by the new risk frameworks depends on the extent to which internal audit, which is the strategic co-partner of the organization, extends the scope of risk management activities to the highest possible level, taking into account certain conditions. As a result of the tests conducted to reveal the differences between the limits of the risk responsibilities of internal audit and the current situation, which is the main purpose of our research, it was found that there is no difference between the opinions in terms of core tasks and never-to-undertake tasks of internal audit. The opinions obtained emphasize that internal audit does not adequately undertake tasks undertaken in certain circumstances. The reason for the difference lies in the fact that internal audit cannot provide conditions that allow it to undertake such tasks, a lack of management support required to meet requirements, or that internal audit functions do not have the level of professional knowledge and experience to undertake tasks. Internal audit functions should strive to provide the conditions that allow them to undertake these tasks to develop the holistic risk approach advocated by the new frameworks.

As a result of our research, the opinions of 245 internal auditors were obtained. Analyses showed that the opinions of internal auditors working in the private sector on main duties were significantly higher than those of public sector employees. On the other hand, the opinions of public sector employees on tasks assumed under certain conditions are significantly higher than those of private sector employees. The findings indicate that internal audit in the private sector is expected to undertake more tasks in risk management and that the conditions affecting internal audit in the public sector have been fulfilled or that necessary top management support is provided.

The opinions were analyzed in terms of demographic variables. It was found that gender did not affect the opinions. The mean of the opinions of internal auditors over the age of 40 on core tasks is significantly lower than the mean of young participants and mean of opinions about tasks assumed under certain conditions is significantly higher. On the other hand, it was 
determined that the mean of the opinions of auditors with a high level of professional experience (over 12 years) regarding tasks assumed under certain conditions was significantly higher than the mean of inexperienced (under 7 years).

The new ERM frameworks emphasize that the use of the new technologies referred to as Industry 4.0 elements in risk management can play a key role. Development of an organization's ERM capabilities depends on the use of advanced technologies such as automation, artificial intelligence, and machine learning in risk management activities. In particular, the benefits of big data and analytics to the audit profession will facilitate the development and internal audit of risk management activities. Advanced data analytics and visualization tools will provide a better understanding of both the positive and negative effects of risks. On the other hand, the paradigm advocated in the new ERM frameworks argues that the jargon problem in enterprises can be solved through a common framework, common processes and an integrated model. Development of a common risk jargon adopted by all functions of the business allows for easier discussion of culture, capabilities and activities involved in risk management processes. The findings of our study showed that the role of internal audit should be undertaken by use of new technologies that enable continuous auditing, adoption of a common risk jargon in the enterprise, and at least some level of technology knowledge to guide IT professionals. On the other hand, the participants believe that these new tasks are not adequately undertaken by internal audit in practice. Internal audit functions should update themselves in order to have the knowledge and skills necessary to adapt to the new ERM paradigm and to respond to the new expectations of a changing world.

The study provided descriptive information on the role of internal auditors in ERM in the ideal situation and the current situation. The results of our study were compared with results of a similar study in the literature. Our findings showed that the perceptions of participants about internal auditors' ERM duties increased over the years. The findings of our study showed that the mean of the opinions about core tasks was significantly higher than the mean obtained in the other two studies. On the other hand, there was a consensus among views on tasks that should never be undertaken. This finding can be explained by the fact that independence and objectivity are the red line of the internal audit profession. Our findings show that internal auditors are more aware of core tasks they should undertake in ERM. Regulations made by IIA and the new ERM frameworks are the most important drivers of awareness raising. Today, ERM has become an important area of responsibility for internal auditors.

Some limitations should be considered when interpreting the results presented in our study. One of them is the potential to threaten internal validity of the research due to the loss of control caused by online delivery of the questionnaire, since it is almost impossible to reach potential participants in the same place. On the other hand, research was conducted on internal auditors of TIDE members. This increases the likelihood of the participants having a higher level of knowledge and objectivity than the total internal audit universe. While this may seem to be an advan- 
tage, it may also create doubts about generalizability of findings. In addition, due to economic conditions, participation is limited to Turkey. Thus, our findings were compared with other limited samples. This election, however, prevented achievement of general global views. Finally, the IIA limited internal auditors' ERM duties to three categories. Our research is based on the task categories determined by the IIA. Important issues, such as impact of internal auditors' characteristics on ERM activities, level of implementation of ERM of organizations, or the relationship between the audit committee, board of directors, and senior management with ERM are excluded from the scope of our research. Eliminating any limitations is a new research opportunity.

Peer-review: Externally peer-reviewed.

Conflict of Interest: The author has no conflict of interest to declare.

Grant Support: The author declared that this study has received no financial support.

\section{References}

Anders, S. B. (2019). COSO's Newest ERM Guidance. The CPA Journal, 89(3), 66-67.

Anderson, Doug. (2017). COSO ERM: Getting risk management right: Strategy and organizational performance are the heart of the updated framework. Internal Auditor, 74(5), 38-43.

Beasley, M. S., Clune, R., \& Hermanson, D. R. (2005). ERM: A status report. Internal Auditors, February, 62(1), 67-73.

Beasley, M. S., Clune, R., \& Hermanson, D. (2006). The impact of enterprise risk management on the internal audit function. Kennesaw, GA: Kennesaw State University Press.

Beasley, M. S., Clune, R., \& Hermanson, D. (2005). Enterprise risk management: An empirical analysis of factors associated with the extent of implementation. Journal of Accounting and Public Policy, 24(6), 521-531.

Castanheira, N., Rodrigues, L. L. and Craig, R. (2010). Factors associated with the adoption of risk-based internal auditing. Managerial Auditing Journal, 25(1), 79-98.

Cohen, J., Krishnamoorthy, G., \& Wright, A. (2017). Enterprise risk management and the financial reporting process: The experiences of audit committee members, CFO s, and external auditors. Contemporary Accounting Research, 34(2), 1178-1209.

Committee of Sponsoring Organizations of the Treadway Commission (COSO). (2004). Enterprise Risk Management Framework (Draft), Amerika: COSO.

Committee of Sponsoring Organizations of the Treadway Commission (COSO). (2017). Enterprise Risk Management Aligning with Strategy and Performance. Amerika: COSO.

Farrell, M., \& Gallagher, R. (2015). The valuation implications of enter-prise risk management maturity. Journal of Risk and Insurance, 82(3), 625-657.

Flanders, K. (2018). An Appetite for Risk: Internal audit departments may need to recalibrate to accept more risk. Internal Auditor, 75(2), 60-66.

Fox, C. (2018). Understanding the New ISO and COSO Updates. Risk Management, 65(6), 4-7.

Fraser, I., \& Henry, W. (2007). Embedding risk management: Structures and approaches. Managerial Auditing Journal, 22(4), 392-409.

George, D., \& Mallery, P. (1995). SPSS/PC+ step by step: A simple guide and reference. Belmont, CA: Wadsworth Publishing Company.

Gramling, A. \& Myers, P. (2006). Internal Auditing’s Role in ERM. Internal Auditor, April, 52-58. 
Herron, A. \& Dholabhai, M. (2017). COSO Enterprise Risk Management Framework- Integrating Strategy and Performance. New York: PwC Governance Insights Center.

Institute of Internal Auditors (IIA). (2004). The Role of Internal Auditing in Enterprisewide Risk Management. London: The Institute of Internal Auditors UK and Ireland.

Institute of Risk Management (IRM). (2018). A Risk Practitioners Guide to ISO 31000: 2018. United Kingdom, London: The Institute of Risk Management UK.

Institute of Internal Auditors (IIA). (2010). Uluslararası Mesleki Uygulama Çerçevesi (UMUÇ) Uluslararası Iç̧ Denetim Standartları. Çeviri: Türkiye İç Denetim Enstitüsü (TIDE). İstanbul: Lebib Yalkın Yayımları.

Paape, L., \& Speklè, R. F. (2012). The adoption and design of enterprise risk management practices: An empirical study. European Accounting Review, 21(3), 533-564.

Pierce, E. M., Goldstein, J., \& Pierce, E. (2016). Moving From Enterprise Risk Management to Strategic Risk Management: Examining the Revised COSO ERM Framework. In 14th Global Conference on Busness and Economics, (October).

Pickett, K. H. S. (2011). The Essential Guide to Internal Auditing. West Sussex: John Wiley \& Sons.

Prewett, K., \& Terry, A. (2018). COSO's updated enterprise risk management framework - a quest for depth and clarity. Journal of Corporate Accounting \& Finance, 29(3), 16-23.

Prinsenberg, M., \& Sluis, R. V. D. (2017). COSO Enterprise Risk Management Framework-Integrating Strategy and Performance. Netherlands, Den Bosch: PricewaterhouseCoopers.

Reding, F. K. Sobel, P. J. Anderson, L. U., Head, M. J. Ramamoorti, S. Salamasick, M., \& Riddle, C. (2013). Internal Auditing: Assurance\& Consulting Services. Altomonte Springs: The IIA Research Foundation.

Richtermeyer, S. B. (2018). Enterprise Risk Management Integrating with Strategy and Performance. USA, Massachusetts: COSO.

Sarens, G., \& De Beelde, I. (2006). Internal auditors' perception about their role in risk management: A comparison between US and Belgian companies. Managerial Auditing Journal, 21(1), 63-80.

Shortreed, J., Fraser, J., Purdy, G., \& Schanfield, A. (2012). The Future Role of Internal Audit in (Enterprise) Risk Management. The Journal of Finance, 1-13.

Sobel, P. J. (2018). COSO ERM: Integrating with Strategy and Performance. The Institute of Internal Auditors International Conferance, UAE, Dubai, 6-9 May1s 2018.

Steffee, S. (2016). COSO drafts ERM framework: long-awaited revision addresses changes in business environment and risk. Internal Auditor, 73(4), 13-15.

Thabit, T. (2019). Determining the Effectiveness of Internal Controls in Enterprise Risk Management based on COSO Recommendations. In International Conference on Accounting, Business Economics and Politics, April.

Tabachnik, B. G., \& Fidell, S. L. (2013). Multicollinearity and singularity. Using multivariate statistics. Boston: Pearson Education Inc, 2(013), 88-91.

Tillinghast, P. T. (2004). Adding value through risk and capital management. New York: Tillinghast-Towers Perrin.

Walker, P. L., Shenkir, W. G., \& Barton, T. L. (2002). Enterprise risk management: pulling it all together. Altamonte Springs, FL: Institute of Internal Auditors Research Foundation.

Wright, C. (2018). The CAE-CRO relationship: Chief audit executives and chief risk officers can collaborate in many ways to ensure the organization manages risks effectively. Internal Auditor, 75(1), 31-36.

Zwaan, L. D., Stewart, J. ve Subramaniam, N. (2011). Internal audit involvement in enterprise risk management. Managerial Auditing Journal, 26(7), 586-604. 